\title{
Identification of Differentially Expressed Genes in Hepatic HepG2 Cells Treated with Acetaminophen Using Suppression Subtractive Hybridization
}

\author{
Kazuhiro Iguchi, Yukari TaKahashi, Yoko Kaneto, Masafumi Kubota, Shigeyuki Usui, and \\ Kazuyuki HiRAno* \\ Laboratory of Pharmaceutics, Gifu Pharmaceutical University; 5-6-1 Mitahora-higashi, Gifu 502-8585, Japan. \\ Received March 10, 2005; accepted April 27, 2005; published online May 9, 2005
}

\begin{abstract}
Acetaminophen (APAP) is widely used for the treatment of pain and fever. Although it is safe at therapeutic doses, APAP is toxic at higher doses and can cause severe damage to the liver. To clarify the mechanism of APAPrelated liver damage, we attempted the identification of the differential gene expression in response to APAP treatment in hepatic HepG2 cells. In the present study, we used the technique of suppression subtractive hybridization (SSH) for the identification of the differentially expressed genes between untreated and treated cells and identified 14 candidate genes showing increased expression in response to APAP treatment. RT-PCR and real-time RT-PCR analysis confirmed that the expression of two genes was increased within $24 \mathrm{~h}$ following APAP treatment. Among them, only lysyl hydroxylase 2 expression was increased in a time- and dose-dependent manner. Furthermore, the expression of lysyl hydroxylase 2 was shown to be increased in the livers of APAP-treated mice compared to untreated controls. The increased expression of lysyl hydroxylase 2 was also observed when the cells were exposed to other hepatotoxins, ethanol and isoniazid. Since lysyl hydroxylase 2 is known to be a key enzyme of liver fibrosis, the increased expression of lysyl hydroxylase 2 may be involved in hepatotoxins-related liver fibrosis.
\end{abstract}

Key words acetaminophen; lysyl hydroxylase 2; liver fibrosis; hepatotoxicity; HepG2; suppression subtractive hybridization $(\mathrm{SSH})$

Acetaminophen ( $N$-acetyl-p-aminophenol; paracetamol; APAP) is a widely used drug for the treatment of pain and fever, but overdose produces severe hepatotoxicity in humans and experimental animals. ${ }^{1,2}$ APAP hepatotoxicity is due to its biotransformation to a reactive metabolite, $N$-acetyl- $p$ benzoquinone imine (NAPQI) by cytochrome P450 (CYP), leading to cellular glutathione depletion by NAPQI conjugation followed by covalent binding of NAPQI to cellular proteins. ${ }^{3,4)}$ APAP toxicity was not observed in CYP1A2 and CYP2E1 double-null mice, indicating that the formation of the metabolites of APAP by the CYPs is a critical step in the initiation phase of the hepatotoxicity. ${ }^{5)}$ Thus, it is indisputable that the reactive metabolite of APAP plays an essential role for the initiation phase of APAP-induced hepatotoxicity. However, in the progression phase following initiation, there is almost no information besides the fact that chemokines are associated with hepatocytes regeneration following toxicity. ${ }^{6}$

Since drug metabolism is impaired in patients with liver disease, the total amount of non-metabolized drug in the serum is increased in the patients with damaged liver. ${ }^{78}$ In the case of hepatotoxicity induced by APAP, high level of non-metabolized APAP in the serum of the patients has been observed. ${ }^{9)}$ Therefore, evaluation of the effect of non-metabolized APAP on hepatocytes is required for full understanding of the progression phase of APAP-induced hepatotoxicity.

There are several studies on the gene expression profiles associated with hepatotoxicity in vitro and in vivo. ${ }^{10-12)}$ These reports reveal the specific gene expression profiles from several types of hepatotoxins using microarray technology. The DNA microarray is a useful technology that was developed as a way to simultaneously evaluate the relative levels of large numbers of mRNA gene transcripts. However, the technology is limited by its insensitivity to transcripts of low abundance. ${ }^{13)}$ In another experimental approach, suppression subtractive hybridization ( $\mathrm{SSH}$ ) was also employed to identify differentially regulated genes. This method makes it possible to detect some low abundance transcripts because of a normalization step to equalize the abundance of target in the subtracted cDNA population. ${ }^{14,15}$

In the present study, to clarify the effect of APAP on hepatic cells, we investigated the gene increased in APAPtreated HepG2 cells, which show low metabolic activity for APAP. The identification of the differentially expressed genes was performed with the SSH technique and two genes that had changed their expression levels in APAP-treated HepG2 cells were determined.

\section{MATERIALS AND METHODS}

Materials APAP was purchased from Merck Hoei (Osaka, Japan). Polymerase chain reaction (PCR) primers were purchased from Sigma Genosys (Ishikari, Japan). All other chemicals were of analytical grade or equivalent, and purchased commercially.

Cell Culture Human hepatic HepG2 cells were purchased from American Type Tissue Collection (ATCC, Rockvill, MD, U.S.A.), and cultured in Dulbecco's modified Eagle's medium (DMEM) with $10 \%$ fetal calf serum under a humidified atmosphere with $5 \% \mathrm{CO}_{2}$ at $37^{\circ} \mathrm{C}$.

Cell Proliferation Cell proliferation was evaluated by measurement of the fluorescence intensity in the presence of alamar blue (Wako, Osaka, Japan), as described previously. ${ }^{16)}$ Briefly, cells were seeded in 96-well multidishes (SUMILON, Tokyo, Japan) at a density of $8 \times 10^{3}$ cells/well, and APAP was added to the culture medium. After $24 \mathrm{~h}$, alamar blue solution was added to the medium, and the plates were incubated for $1 \mathrm{~h}$. The fluorescence intensity was measured using a fluorescent plate reader (Cytofluor 2350; Millipore, 
Bedford, MA, U.S.A.) with excitation and emission wavelengths of 530 and $590 \mathrm{~nm}$, respectively.

Preparation of Subtracted cDNA Libraries HepG2 cells were treated with or without $5 \mathrm{~mm}$ APAP for $24 \mathrm{~h}$ and total RNAs were prepared using TRIzol regent (Invitrogen, Carlsbad, CA, U.S.A.), according to the manufacturer's instructions. Messenger RNA was isolated from the total RNA using Oligotex-dT30〈Super $\rangle$ (Takara, Otsu, Japan), and double-strand cDNA was synthesized using a cDNA synthesis kit (Takara). The subtractive cDNA library was constructed with an SSH technique, as described by Diatchenko et $a l .{ }^{14,15)}$ The cDNA from HepG2 cells treated with APAP was used as the tester cDNA and the cDNA from untreated HepG2 cells was used as the driver cDNA. The differential PCR products obtained after two rounds of subtraction were cloned into pBluescript II KS+.

Differential Screening of the Subtracted Library Bacterial colonies were picked up and amplified with PCR using $\mathrm{T} 3$ and T7 primers. The PCR products were denatured in an equal volume of $0.6 \mathrm{M} \mathrm{NaOH}$ and dot-blotted in duplicate onto nylon membranes (Nytran; Schleicher \& Schuell, Keene, NH, U.S.A.). The membranes were soaked in $0.5 \mathrm{M}$ Tris- $\mathrm{HCl}$, pH 7.4 for $5 \mathrm{~min}$, washed with water and crosslinked with a CL-1000 ultraviolet cross-linker (UVP, Upland, CA, U.S.A.). The membranes were then hybridized with biotin-labeled double-stranded cDNA derived from driver and tester mRNA, and washed with $2 \times \mathrm{SSC}$ and $0.2 \times \mathrm{SSC}$. The blots were developed with chemiluminescence CDP-Star substrate (Amersham Biosciences, NJ, U.S.A.), exposed to $\mathrm{X}$-ray film, and then the differentially expressed clones were selected. Plasmids from the selected clones were isolated by alkaline lysis/PEG precipitation procedure ${ }^{17)}$ and the DNA inserts were sequenced using a DNA sequencer (CEQ2000XL; Beckman-Coulter, Fullerton, CA, U.S.A.). The obtained sequence data were analyzed for homology to known genes using the Basic Local Alignment Tool (BLAST).

RNA Isolation, Semiquantitative Reverse Transcription-PCR (RT-PCR), and Real-Time RT-PCR HepG2 cells were cultured in $3.5 \mathrm{~cm}$ dishes (Nalge Nunc, Rochester, NY, U.S.A.), and treated with drugs at various concentrations for $24 \mathrm{~h}$ or at $5 \mathrm{~mm}$ for various lengths of time. Total RNA was isolated using TRIzol reagent, according to the manufacturer's instructions. Extracted RNA was dissolved in diethylpyrocarbonate-treated water and quantified by measuring the absorbance at $260 \mathrm{~nm}$. Aliquots of $5 \mu \mathrm{g}$ of total RNA were used to synthesize the first-strand cDNA with SuperScript III (Invitrogen) and subjected to PCR amplification with the oligonucleotide primers listed in Table 1.

The optimal PCR conditions were determined according to the amount of amplification product in proportion to that of input RNA. PCR was performed under the following conditions: denaturation at $94^{\circ} \mathrm{C}$ for $15 \mathrm{~s}$, annealing at each temperature (as shown in Table 1) for $30 \mathrm{~s}$, and extension at $72{ }^{\circ} \mathrm{C}$ for $30 \mathrm{~s}$, then prolonged extension at $72{ }^{\circ} \mathrm{C}$ for $7 \mathrm{~min}$. For glyceraldehyde-3-phosphate dehydrogenase (G3PDH), denaturation at $94^{\circ} \mathrm{C}$ for $45 \mathrm{~s}$, annealing at $60^{\circ} \mathrm{C}$ for $45 \mathrm{~s}$, and extension at $72^{\circ} \mathrm{C}$ for $2 \mathrm{~min}$. G3PDH served as an internal RNA control to allow comparison of RNA levels among different specimens. After PCR, the reaction products were resolved on $1.75 \%$ agarose gels and visualized with ethidium bromide.

Real-time monitoring of PCR reactions was performed using the iCycler iQ Real-Time PCR Detection System (BioRad Laboratories, Hercules, CA, U.S.A.) with the iQ SYBRGreen Supermix reagents (Bio-Rad Laboratories). The PCR was performed under the following conditions: 40 cycles of denaturation at $94^{\circ} \mathrm{C}$ for $15 \mathrm{~s}$, annealing at each temperature (Table 1) for $30 \mathrm{~s}$, and extension at $72^{\circ} \mathrm{C}$ for $30 \mathrm{~s}$.

Animal Protocol Animal treatments were approved by the Animal Care and Use Committee of Gifu Pharmaceutical University. Adult C57/BL male mice weighing 25 to $30 \mathrm{~g}$ were used. Mice were housed in an environmentally controlled room $\left(25^{\circ} \mathrm{C}, 12 \mathrm{~L}: 12 \mathrm{D}\right.$ cycle $)$ and fed standard food pellets and water ad libitum. The mice were randomly divided into two groups and treated with daily intraperitoneal (i.p.) injections of APAP $(250 \mathrm{mg} / \mathrm{kg})$ or saline. This APAP dose was chosen to produce moderate hepatic necrosis without significant mortality. ${ }^{18)}$ After $7 \mathrm{~d}$, the mice were sacrificed and liver tissue was collected from each animal. The collected tissue samples were frozen in dry ice/ethanol and stored at $-80^{\circ} \mathrm{C}$ until use.

Extraction of total RNA was performed in the same way as described above. The obtained cDNA samples were subjected to PCR amplification with the oligonucleotide primers listed in Table 1 under the following conditions: denaturation at $94^{\circ} \mathrm{C}$ for $15 \mathrm{~s}$, annealing at each temperature (Table 1) for $30 \mathrm{~s}$, and extension at $72^{\circ} \mathrm{C}$ for $30 \mathrm{~s}$.

Statistical Analysis The significance of differences between two groups was calculated by Student's $t$ test, and the significance of differences between multiple groups were assessed by one-way analysis of variance followed by the Dunnet's test.

\section{RESULTS}

Identification of the Genes Induced by APAP in Hepatic HepG2 Cells To evaluate the effect of APAP on hepatic cell proliferation, HepG2 cells were incubated with various concentrations of APAP for $24 \mathrm{~h}$. The proliferation of HepG2 cells was inhibited by APAP in a dose-dependent manner (Fig. 1), and the morphology of the treated cells was not changed until $5 \mathrm{~mm}$ treatment (data not shown). We therefore used the concentration of $5 \mathrm{~mm}$ APAP for SSH to identify the APAP-inducible genes in order to eliminate the potentially confusing effects of cell death. Following SSH, 146 cDNA clones were randomly chosen and rescreened for differential gene expression by dot-blot hybridization, and were then sequenced. The screening indicated that 14 clones were up-regulated, as shown in Table 2; the clones were then sequenced. Next, semiquantitative RT-PCR was performed to confirm that the transcript was differentially expressed. Ten function-known genes among 14 genes were examined. Figure 2 shows that the expression of lysyl hydroxylase 2 mRNA in HepG2 cells was increased due to the treatment with APAP. The altered expression of thymidylate synthase was also seen in APAP-treated cells. There were no obvious changes in other genes.

Real-Time RT-PCR Analysis of Identified Genes in APAP-Treated HepG2 Cells We next performed quantitative real-time RT-PCR analysis to further confirm the differential expression of the identified genes (lysyl hydroxylase 2, 
Table 1. Sequences of Oligonucleotide Primers for RT-PCR and Real-Time RT-PCR

\begin{tabular}{|c|c|c|c|}
\hline Gene name & Sequence & $\begin{array}{c}\text { Temperature }{ }^{a)} \\
\left({ }^{\circ} \mathrm{C}\right)\end{array}$ & Cycles $^{b)}$ \\
\hline \multicolumn{4}{|l|}{ Human } \\
\hline \multicolumn{4}{|l|}{ Actin $\gamma$} \\
\hline Sense & 5'-AGTAACAGCCCACGGTGTTC-3' & 63 & 20 \\
\hline Antisense & 5'-GTTGGAAAGTCCAAGCCGTA-3' & & \\
\hline \multicolumn{4}{|l|}{ Actin related protein } \\
\hline Sense & 5'-GAAAGCACTAGCAGGCATCA-3' & 66 & 25 \\
\hline Antisense & 5'-GGAGTGCTTCCAATCCСТCTC-3' & & \\
\hline \multicolumn{4}{|l|}{$\mathrm{ADP} / \mathrm{ATP}$ carrier protein } \\
\hline Sense & 5'-ACAGGCCCTTAATCCCATCA-3' & 66 & 22 \\
\hline Antisense & 5'-CGGTGACTGCCTGGTTAAGA-3' & & \\
\hline \multicolumn{4}{|l|}{ Diaphorase } \\
\hline Sense & 5'-GTCCATCCCAACTGACAACC-3' & 63 & 20 \\
\hline Antisense & 5'-GGAAGCCTGGAAAGATACCC-3' & & \\
\hline \multicolumn{4}{|l|}{ Intramembrane protease 3} \\
\hline Sense & 5'-CCAGGTCCTTGGTGTCAAAT-3' & 63 & 24 \\
\hline Antisense & 5'-TACCAGCTGCTCTTCACACA-3' & & \\
\hline \multicolumn{4}{|l|}{ Lysyl hydroxylase 2} \\
\hline Sense & 5'-CCCTTTGTCTCGCTCCTTAT-3' & 63 & 24 \\
\hline Antisense & 5'-AAGCGGGATAGAGGGAAGTT-3' & & \\
\hline \multicolumn{4}{|l|}{ Thymidylate synthase } \\
\hline Sense & 5'-AGTTGGATGCGGATTGTACC-3' & 63 & 23 \\
\hline Antisense & 5'-CCAAAGCTCAGGATTCTTCG-3' & & \\
\hline \multicolumn{4}{|c|}{ Voltage dependent anion channel } \\
\hline Sense & 5'-AAAAACAAATTGAGTGGTGAGAA-3' & 63 & 23 \\
\hline Antisense & 5'-GCTTGGAAGTGTCTGTGTGA-3' & & \\
\hline \multicolumn{4}{|c|}{ Xenotropic and polytropic retrovirus receptor } \\
\hline Sense & 5'-TAACCCCCAGACCCAAATGA-3' & 63 & 25 \\
\hline Antisense & 5'-GGTAATAGCTGCCCTTCCAC-3' & & \\
\hline \multicolumn{4}{|c|}{ (5) } \\
\hline Sense & 5'-CAATGACCCCTTCATTGACC-3' & 60 & 19 \\
\hline Antisense & 5'-GACAAGCTTCCCGTTCTCAG-3' & & \\
\hline \multicolumn{4}{|l|}{ Mouse } \\
\hline \multicolumn{4}{|l|}{ Lysyl hydroxylase 2} \\
\hline Sense & 5'-TTCTGAACGAGCCTGTGATG-3' & 60 & - \\
\hline Antisense & 5'-ССТCССТGAAAATCCТСТCС-3' & & \\
\hline \multicolumn{4}{|c|}{ с } \\
\hline Sense & 5'-TGTTCCTACCCCCAATGTGT-3' & 60 & - \\
\hline Antisense & 5'-TGTGAGGGAGATGCTCAGTG-3' & & \\
\hline
\end{tabular}

a) Annealing temperature. b) Number of PCR cycles (for RT-PCR).

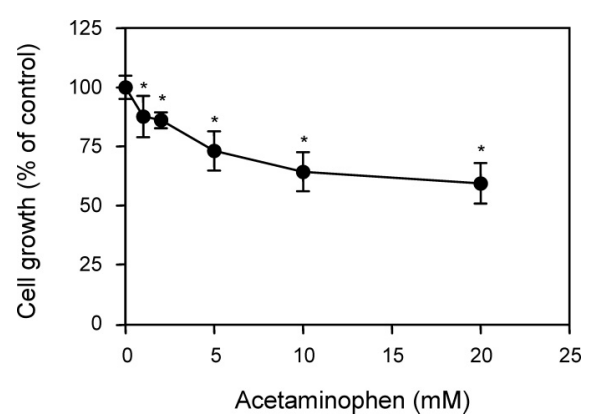

Fig. 1. Effect of Acetaminophen on the Growth of HepG2 Cells

HepG2 cells were cultured in the presence of acetaminophen for $24 \mathrm{~h}$. Cell growth was examined by alamar blue assay. Values represent the means \pm S.D. from ten different incubations. $* p<0.01$ versus control.

thymidylate synthase). As shown in Fig. 3, APAP treatment induced lysyl hydroxylase 2 mRNA expression in a dose- and time-dependent manner. The expression level of lysyl hydroxylase $2 \mathrm{mRNA}$ in the treated cells was approximately 4.0 -fold higher than that in the untreated cells, $48 \mathrm{~h}$ after treatment with APAP. The mRNA expression level of thymidylate synthase was increased about 1.2 -fold at $5 \mathrm{~mm}$
Table 2. Up-Regulated Genes in APAP-Treated HepG2 Cells

\begin{tabular}{l}
\hline \multicolumn{1}{c}{ Identified genes } \\
\hline Actin $\gamma$ \\
Actin-related protein \\
ADP/ATP carrier protein \\
Diaphorase \\
Intramembrane protease 3 \\
Lysyl hydroxylase 2 \\
PM5 \\
Ribosomal protein L19 \\
S15a \\
Similar to caenorhabditis elegans protein \\
Similar to putative insulin-like growth factor 2 associated protein \\
Thymidylate synthase \\
Voltage-dependent anion channel \\
Xenotropic and polytropic retrovirus receptor
\end{tabular}

APAP treatment, but was then obviously decreased at $10 \mathrm{~mm}$ and above.

To examine whether the increase of lysyl hydroxylase 2 mRNA expression is observed only in cells treated with APAP, we analyzed the expression level of lysyl hydroxylase 


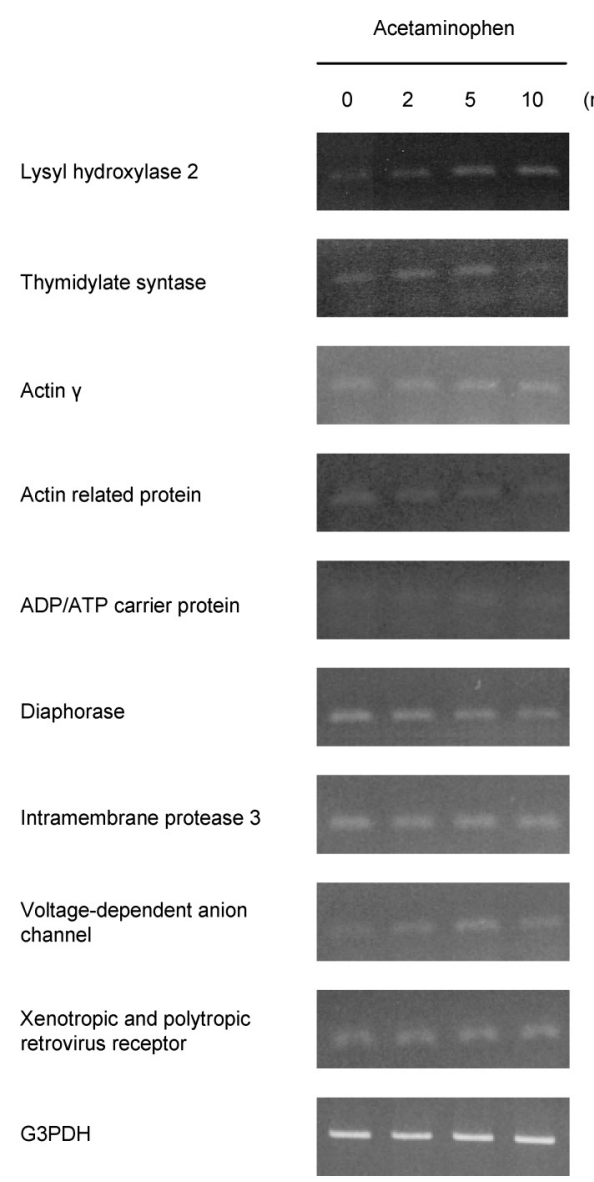

Fig. 2. RT-PCR Analysis of Isolated Genes in APAP-Treated HepG2 Cells HepG2 cells were incubated with the indicated concentrations of APAP for $24 \mathrm{~h}$. After incubation, total RNA was isolated and subjected to RT-PCR analysis. The products were resolved on $1.75 \%$ agarose gels and visualized with ethidium bromide. Data shown are representative of four separate experiments.

2 in other hepatotoxin-treated HepG2 cells with semiquantitative RT-PCR analysis. Figure 4B indicates that lysyl hydroxylase 2 expression was also increased in isoniazid and ethanol-treated HepG2 cells. No change in the cell viability was observed after isoniazid and ethanol treatment up to $2 \mathrm{~mm}$ and 5.5\%, respectively (Fig. 4A).

Expression of Lysyl Hydroxylase 2 mRNA in APAPTreated Mice We next investigated whether the identified genes were increased in APAP-exposed mice in vivo. As shown in Fig. 5, real-time RT-PCR analysis revealed that lysyl hydroxylase $2 \mathrm{mRNA}$ expression in the APAP-treated mice liver was increased approximately 2.1 -fold compared with the control. However, there was no significant difference in the mRNA expression level of thymidylate synthase between the APAP-treated and non-treated mice.

\section{DISCUSSION}

The SSH technique was used to identify genes induced by APAP in hepatic HepG2 cells and we found increased expression of lysyl hydroxylase 2 , which functions in the formation of collagen polymerization. ${ }^{19-21)}$ Although APAP-induced hepatotoxicity is mediated by the reactive electrophilic metabolite NAPQI, converted from APAP by CYP, ${ }^{4)}$ the expression levels of CYP in HepG2 cells are very low compared with those in normal hepatocytes ${ }^{22)}$ suggesting that the
(A) Lysyl hydroxylase 2
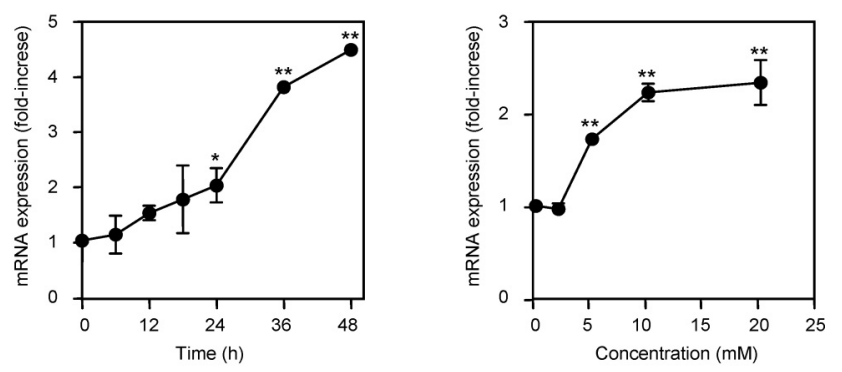

(B) Thymidylate synthase
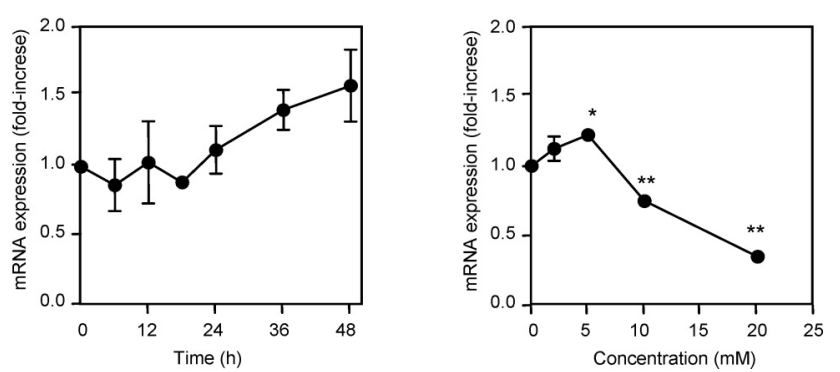

Fig. 3. Dose and Time-Effects of APAP on the Expression of Differentially Expressed Genes in HepG2 Cells

HepG2 cells were incubated with the indicated concentrations of APAP for $24 \mathrm{~h}$ or $5 \mathrm{~mm}$ APAP for the indicated times. After incubation, total RNA was isolated and subjected to real-time RT-PCR analysis. The results were normalized to G3PDH housekeeping gene expression. (A) Lysyl hydroxylase 2. (B) Thymidylate synthase. Values represent the means \pm S.D. from four separate experiments. $* p<0.05, * * p<0.01$ versus control.

(A)
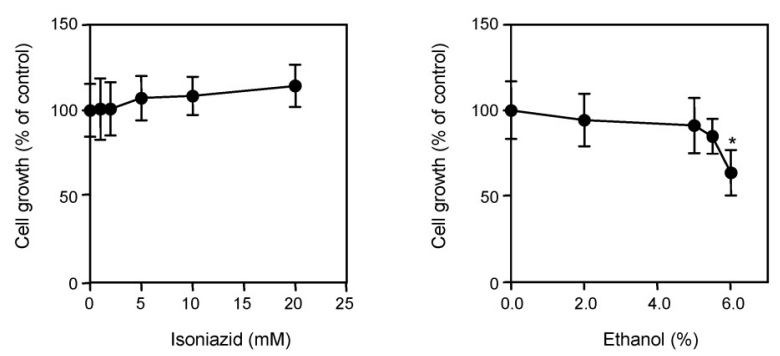

(B)

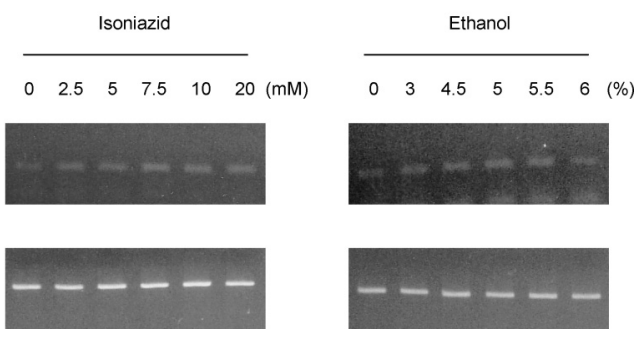

Fig. 4. Effect of Hepatotoxins on the Expression of Lysyl Hydroxylase 2 in HepG2 Cells

HepG2 cells were incubated with the indicated concentrations of isoniazid and ethanol for $24 \mathrm{~h}$. (A) Cell growth was examined by alamar blue assay. Values represent the means \pm S.D. from ten different incubations. $* p<0.01$ versus control. (B) Total RNA was isolated and subjected to RT-PCR analysis. The products were resolved on $1.75 \%$ agarose gels and visualized with ethidium bromide. Data shown are representative of four separate experiments. 


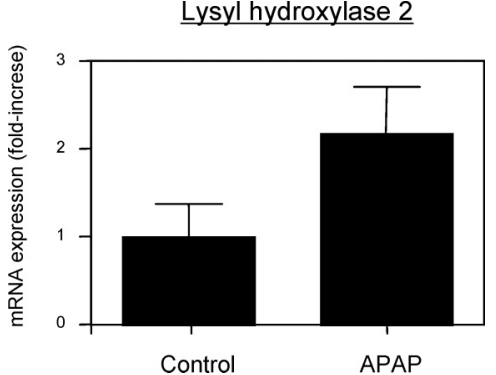

Fig. 5. Effect of Lysyl Hydroxylase 2 Expression in APAP-Treated Mice

Mice were treated with either APAP $(250 \mathrm{mg} / \mathrm{kg}$ i.p., $n=10)$ or vehicle $(n=7)$ once a day for $6 \mathrm{~d}$. Total RNA was purified from APAP-treated and vehicle-treated mice, an subjected to real-time RT-PCR analysis. The results were normalized to G3PDH housekeeping gene expression. Values represent the mean \pm S.E.M.

reactive intermediate would not be expected to appear in APAP-treated HepG 2 cells. Therefore, the altered expression of identified genes must have resulted from the direct effect of APAP itself, not from the cytotoxicity of its metabolites. The increased expression of lysyl hydroxylase 2 after APAP treatment provides further insight into the mechanism of APAP-mediated liver damage.

Lysyl hydroxylase catalyzes the posttranslational hydroxylation of lysine residues in collagen. ${ }^{19-21)}$ Hydroxylation of lysine residues in collagen molecules by lysyl hydroxylase is essential for the formation and stabilization of collagen crosslinks, as well as the oxidation of lysine residues by lysyl oxidase and hydroxylation of proline residues by prolyl hydroxylase. ${ }^{19)}$ The development of liver fibrosis requires not only the induction of collagen synthesis, but also the stabilization of collagen crosslinks. ${ }^{19}$ ) In fact, increased expressions of collagen processing enzymes (lysyl hydroxylase, lysyl oxidase and prolyl hydroxylase) were observed in $\mathrm{CCl}_{4}$ induced and dimethylnitrosamine-induced liver fibrosis in rats. $^{23-25)}$ Recently, overhydroxylation of collagen telopeptide lysine residues was reported to be critical in the irreversible accumulation of collagen in fibrosis and the overhydroxylation was catalyzed by lysyl hydroxylase $2,{ }^{26,27)}$ identified in this study as being differentially expressed in APAPtreated HepG2 cells. Moreover, long-term low-dose treatment with APAP was reported to induce liver fibrosis in humans. ${ }^{28,29)}$ These reports are consistent with the result from this study that increased expression of lysyl hydroxylase 2 in APAP-treated mouse without significant mortality. Taking the above reports and this study into consideration, we can suggest that the increased lysyl hydroxylase 2 expression induced by APAP may be involved in the development of liver fibrosis.

In our study, the expression of lysyl hydroxylase 2 mRNA was increased not only in APAP-treated, but also in isoniazid or ethanol-treated cells. The increased expression of lysyl hydroxylase 2 in isoniazid or ethanol-treated cells was observed without reduced cell viability. Moreover, lysyl hydroxylase 2 expression was not changed when HepG2 cells were treated with hepatoprotective agents (ursodeoxy-cholic acid and glycyrrhizin) (data not shown). Taken together, altered expression of lysyl hydroxylase 2 did not result from a non-specific effect of cell death. The molecular mechanism by which APAP induces lysyl hydroxylase 2 is now under investigation.

Thymidylate synthase expression was slightly increased at low APAP, but decreased at higher concentrations (20 mM). Thymidylate synthase functions as an RNA binding protein, and forms a ribonucleoprotein complex with a variety of cellular mRNAs, including c-myc transcription factor. ${ }^{30,31)}$ Increased expression of c-myc was observed in a variety of hepatotoxin-treated animals and cells, including APAP-treated animals. ${ }^{11,12,32,33)}$ Since the translation of c-myc mRNA is regulated by the interaction with thymidylate synthase, the decreased expression of thymidylate synthase due to APAPtreatment would lead to increased translation of c-myc mRNA. Although the mechanism of inhibition of thymidylate synthase expression by APAP is unknown, the decreased expression of thymidylate synthase may be involved in APAP-induced hepatotoxicity.

In this study, we first identified lysyl hydroxylase 2, which is associated with the formation of liver fibrosis, as a differentially expressed gene in APAP-treated hepatic HepG2 cells using the SSH technique. Isoniazid and ethanol also increased the mRNA of lysyl hydroxylase 2 in HepG 2 cells. This finding contributes to the understanding of hepatotoxininduced liver injury.

Acknowledgments This work was supported by a Grantin-aid for Scientific Research (No. 16590115) from the Ministry of Education, Culture, Sports, Science and Technology of Japan.

\section{REFERENCES}

1) Davidson D. G., Eastham W. N., Br. Med. J., 5512, 497-499 (1966).

2) Prescott L. F., Roscoe P., Wright N., Brown S. S., Lancet, 1, 519-522 (1971).

3) Mitchell J. R., Jollow D. J., Potter W. Z., Davis D. C., Gillette J. R., Brodie B. B., J. Pharmacol. Exp. Ther, 187, 185-194 (1973).

4) Dahlin D. C., Miwa G. T., Lu A.Y., Nelson S. D., Proc. Natl. Acad. Sci. U.S.A., 81, 1327-1331 (1984).

5) Zaher H., Buters J. T., Ward J. M., Bruno M. K., Lucas A. M., Stern S. T., Cohen S. D., Gonzalez F. J., Toxicol. Appl. Pharmacol., 152, 193 199 (1998).

6) Hogaboam C. M., Bone-Larson C. L., Steinhauser M. L., Lukacs N. W., Colletti L. M., Simpson K. J., Strieter R. M., Kunkel S. L., FASEB $J ., 13,1565-1574$ (1999).

7) Tanaka, E., J. Clin. Pharm. Ther, 23, 161-170 (1998).

8) Villeneuve J. P., Pichette V., Curr. Drug Metab., 5, 273-282 (2004).

9) Schiodt F. V., Ott P., Christensen E., Bondesen S., Clin. Pharmacol. Ther., 71, 221-225 (2002).

10) Burczynski M. E., McMillian M., Ciervo J., Li L., Parker J. B., Dunn R. T. 2nd., Hicken S., Farr S., Johnson M. D., Toxicol. Sci., 58, 399415 (2000).

11) Ruepp S. U., Tonge R. P., Shaw J., Wallis N., Pognan F., Toxicol. Sci., 65, 135-150 (2002).

12) Reilly T. P., Bourdi M., Brady J. N., Pise-Masison C. A., Radonovich M. F., George J. W., Pohl L. R., Biochem. Biophys. Res. Commun., 282, 321-328 (2001).

13) Evans S. J., Datson N. A., Kabbaj M., Thompson R. C., Vreugdenhil E., De Kloet E. R., Watson S. J., Akil H., Eur. J. Neurosci., 16, 409413 (2002).

14) Diatchenko L., Lau Y. F., Campbell A. P., Chenchik A., Moqadam F., Huang B., Lukyanov S., Lukyanov K., Gurskaya N., Sverdlov E.D., Siebert P. D., Proc. Natl. Acad. Sci. U.S.A., 93, 6025-6030 (1996).

15) Diatchenko L., Lukyanov S., Lau Y. F., Siebert P. D., Methods Enzymol., 303, 349-380 (1999).

16) Iguchi K., Hamatake M., Ishida R., Usami Y., Adachi T., Yamamoto H., Koshida K., Uchibayashi T., Hirano K., Eur. J. Biochem., 253, $766-770$ (1998).

17) Sambrook J., Fritsch E. F., Maniatis T., "Molecular Cloning: a Laboratory Manual," 2nd ed., ed. by Nolan C., Ford N., Ferguson M., Cold Spring Harbor Laboratory Press, New York, 1989, pp. 1.25-1.31. 
18) Salminen W. F., Jr., Voellmy R., Roberts S. M., J. Pharmacol. Exp. Ther, 286, 519-524 (1998).

19) Prockop D. J., Kivirikko K. I., Annu. Rev. Biochem., 64, 403-434 (1995).

20) Valtavaara M., Papponen H., Pirttila A. M., Hiltunen K., Helander H., Myllyla R., J. Biol. Chem., 272, 6831-6834 (1997).

21) Kivirikko K. I., Pihlajaniemi T., Adv. Enzymol. Relat. Areas Mol. Biol., 72, 325-398 (1998).

22) Doostdar H., Duthie S. J., Burke M. D., Melvin W. T., Grant M. H., FEBS Lett., 241, 15-18 (1988).

23) Risteli J., Kivirikko K. I., Biochem. J., 144, 115-122 (1974)

24) Risteli J., Kivirikko K. I., Biochem. J., 158, 361-367 (1976).

25) Siegel R. C., Chen K. H., Greenspan J. S., Aguiar J. M., Proc. Natl. Acad. Sci. U.S.A., 75, 2945-2949 (1978).

26) van der Slot A. J., Zuurmond A. M., Bardoel A. F., Wijmenga C., Pruijs H. E., Sillence D. O., Brinckmann J., Abraham D. J., Black C. M., Verzijl N., DeGroot J., Hanemaaijer R., TeKoppele J. M., Huizinga
T. W., Bank R. A., J. Biol. Chem., 278, 40967-40972 (2003).

27) van der Slot A. J., Zuurmond A. M., van den Bogaerdt A. J., Ulrich M. M., Middelkoop E., Boers W., Karel Ronday H., DeGroot J., Huizinga T. W., Bank R. A., Matrix Biol., 23, 251-257 (2004).

28) Bonkowsky H. L., Mudge G. H., McMurtry R. J., Lancet, 1, 10161018 (1978).

29) O’Dell J. R., Zetterman R. K., Burnett D. A., JAMA, 255, 2636-2637 (1986).

30) Chu E., Takechi T., Jones K. L., Voeller D. M., Copur S. M., Maley G. F., Maley F., Segal S., Allegra C. J., Mol. Cell Biol., 15, 179-185 (1995)

31) Liu J., Schmitz J. C., Lin X., Tai N., Yan W., Farrell M., Bailly M., Chen T., Chu E., Biochim. Biophys. Acta, 1587, 174-182 (2002).

32) Herbst H., Milani S., Schuppan D., Stein H., Lab. Invest., 65, 324 333 (1991).

33) Schmiedeberg P., Biempica L., Czaja M. J., J. Cell. Physiol., 154, 294-300 (1993). 